\title{
Efficient Hydrogen Generation from Ammonia Borane on Skeletal Cu Catalysts Prepared from Cu-Ti Amorphous Alloys
}

\author{
Ai Nozaki ${ }^{1, * 1}$, Somchuen Kittima ${ }^{1, * 1}$, Yasutomo Tanihara ${ }^{1, * 1}$, Yasutaka Kuwahara ${ }^{1,2}$, \\ Tetsutaro Ohmichi ${ }^{1}$, Takashi Kamegawa ${ }^{3}$, Kohsuke Mori ${ }^{1,2}$ and Hiromi Yamashita ${ }^{1,2, * 2}$ \\ ${ }^{1}$ Divisions of Materials and Manufacturing Science, Graduate School of Engineering, \\ Osaka University, Suita 565-0871, Japan \\ ${ }^{2}$ ESICB, Kyoto University, Kyoto 615-8520, Japan \\ ${ }^{3}$ Nanoscience and Nanotechnology Research Center, Research Organization for the 21st Century, \\ Osaka Prefecture University, Sakai 599-8570, Japan
}

The catalytic performances of skeletal $\mathrm{Cu}$ prepared from $\mathrm{Cu}-\mathrm{Ti}$ amorphous alloy heated at various temperatures were tested for the hydrogen generation from ammonia borane. The catalytic activity per surface area decreased with increasing heating temperatures of $\mathrm{Cu}-\mathrm{Ti}$ amorphous alloy. The thermal treatment of $\mathrm{Cu}$-Ti amorphous alloy leads to the high surface area of skeletal $\mathrm{Cu}$. A skeletal $\mathrm{Cu}$ catalyst prepared from heated $\mathrm{Cu}-\mathrm{Ti}$ amorphous alloy at $300^{\circ} \mathrm{C}$ which is a moderate temperature somewhat lower than crystallization temperature, exhibited a higher catalytic activity in this reaction. [doi:10.2320/matertrans.MF201407]

(Received November 4, 2014; Accepted December 17, 2014; Published January 30, 2015)

Keywords: amorphous alloys, skeletal catalyst, copper-titanium alloys

\section{Introduction}

The transition metals, especially noble metals such as $\mathrm{Pt}$ and Pd etc., have been utilized as highly active catalysts in the various reactions. However, $\mathrm{Pt}$ and $\mathrm{Pd}$ are quite expensive and rare. Thereby, it is required to reduce the consumption of $\mathrm{Pt}$ and $\mathrm{Pd}$ and to develop alternative materials. $\mathrm{Cu}$ is a common and active metal in the hydrogenation reaction while it shows lower catalytic activity compared with Pt and Pd. Preparation of skeletal catalyst by extracting the unnecessary component selectively from multi-component alloys by chemical treatment has been applied to obtain metal catalysts with high surface area. ${ }^{1-10)}$ Recently, we reported that the skeletal $\mathrm{Cu}$ catalyst prepared from the $\mathrm{Cu}$-Ti amorphous alloy showed a higher catalytic activity in the hydrogenation reaction compared with that of the corresponding crystalline alloy. ${ }^{11,12)}$

Amorphous alloy has an unique and disordered atomic arrangement. ${ }^{13-19)}$ It was reported that amorphous alloy acted as a catalyst in the reaction of hydrogenation, oxidation and alkylation. ${ }^{20-28)}$ The heat treatment to amorphous alloy leads to phase transitions which are accompanied by gradual structural changes from amorphous to crystalline. ${ }^{29)}$ Therefore, the investigation of the relationship between structural change of $\mathrm{Cu}-\mathrm{Ti}$ amorphous alloy and the catalytic activity of skeletal $\mathrm{Cu}$ is a quite interesting topic.

Recently, the development of highly active catalysts in the hydrogen generation from the hydrogen storage materials is needed for hydrogen fuel cell. The hydrogen storage materials such as formic acid, hydrazine, ammonia borane have attracted much attention because of their high hydrogen content $\left(4.4,12.5,19.6\right.$ mass \%, respectively). ${ }^{30,31)}$ Especially, ammonia borane is one of the most promising candidate owing to its hydrogen content (19.6 mass\%), high stability

\footnotetext{
${ }^{* 1}$ Graduate Student, Osaka University

${ }^{* 2}$ Corresponding author, E-mail: yamashita@mat.eng.osaka-u.ac.jp
}

and non-flammable nature. It has been reported that $\mathrm{Fe}$ amorphous particle showed a higher catalytic activity in the hydrogen-generating reaction from ammonia borane. ${ }^{32)}$ According to this report, amorphous structure is essential for achieving the high activity of Fe nanoparticles. Skeletal $\mathrm{Cu}$ prepared from amorphous alloy are also expected to show specific activities in this reaction owing to their unique structure.

In this study, the relationship between structural transformation of $\mathrm{Cu}$-Ti amorphous alloy and catalytic property of the skeletal $\mathrm{Cu}$ catalyst prepared from $\mathrm{Cu}$-Ti amorphous alloy in the hydrogen-generating reaction from ammonia borane was investigated. Characterization of the obtained skeletal $\mathrm{Cu}$ catalysts was carried out by various spectroscopic methods, and the catalytic performance was tested in the hydrogen generation from ammonia borane.

\section{Experimental Procedure}

\subsection{Preparation of skeletal $\mathrm{Cu}$}

The mother $\mathrm{Cu}-\mathrm{Ti}$ alloy was prepared from pure $\mathrm{Cu}$ and $\mathrm{Ti}$ metals in arc furnace under Ar atmosphere. An amorphous $\mathrm{Cu}-\mathrm{Ti}$ alloy in the shape of ribbon (width; ca. $2 \mathrm{~mm}$, thickness; ca. 10-20 $\mu \mathrm{m}$ ) was prepared from crystalline mother alloy by the rapid quenching method. Figure 1 presents the preparation procedure of skeletal $\mathrm{Cu}$. The prepared $\mathrm{Cu}-\mathrm{Ti}$ amorphous alloy was denoted as aCuTi. The heat treatments of aCuTi were carried out in a temperature range from 100 to $600^{\circ} \mathrm{C}$ under vacuum for $2 \mathrm{~h}$ (heating rate of $3^{\circ} \mathrm{C} \cdot \mathrm{min}^{-1}$ ). The heated $\mathrm{aCuTi}$ is denoted as $\mathrm{CuTi}(\mathrm{T})$, where $\mathrm{T}$ represents heating temperatures $\left(\mathrm{T}=100\right.$ to $\left.600^{\circ} \mathrm{C}\right)$. For extraction of $\mathrm{Ti}$ moieties, aCuTi and $\mathrm{CuTi}(\mathrm{T})$ were treated with aqueous HF solution $\left(1.0 \mathrm{~mol} \cdot \mathrm{L}^{-1}\right)$ for $30 \mathrm{~min}$, and then thoroughly washed with ion-exchanged water. The skeletal $\mathrm{Cu}$ were denoted as $\mathrm{s}-\mathrm{aCu}$ and $\mathrm{s}-\mathrm{Cu}(\mathrm{T})$. 


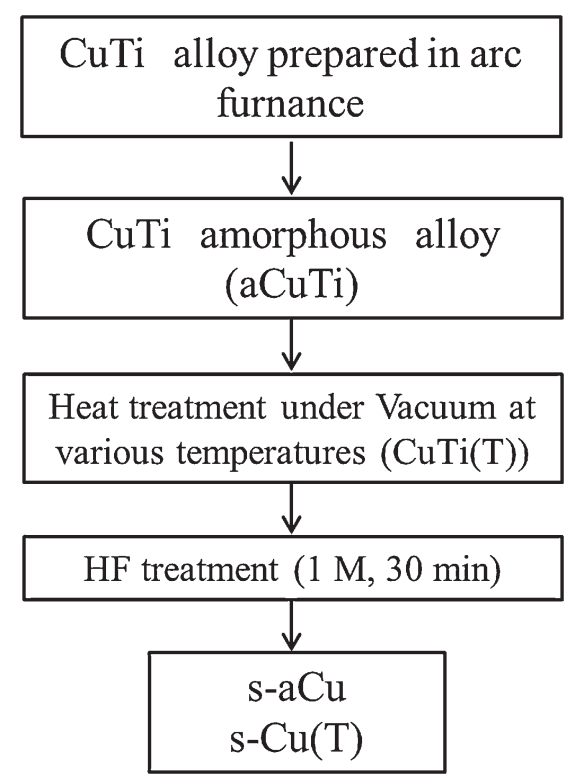

Fig. 1 Diagram of preparation paths for skeletal $\mathrm{Cu}$ catalysts.

\subsection{Characterization}

Crystallinity of the samples was analyzed by X-ray diffraction (XRD, RIGAKU Ultima IV). Surface areas were estimated by the Brunauer-Emmett-Teller (BET) method using krypton physisorption at $77 \mathrm{~K}$ (BEL Japan, Inc. BELSORP max). The surface atomic ratio was analyzed by energy dispersive X-ray spectrometry (EDX, EDAX Ltd. DX-4). The surface morphology of the samples was observed in a FE-SEM (JEOL JSM-6500). Prior to SEM analyses, the sample surfaces were coated with gold/palladium using an ion-sputtering device (JEOL JFC-1100).

\subsection{Catalytic reactions}

The catalytic performances of samples were tested in the hydrogen-generating reaction from ammonia borane. Prior to catalytic reactions, samples (1 piece, length; $1 \mathrm{~cm})$ were treated with hydrogen at $200^{\circ} \mathrm{C}$ for $1 \mathrm{~h}$. The hydrogengenerating reaction from ammonia borane was performed in a quartz reaction vessel. A mixture containing the catalyst (one piece), ammonia borane $(0.65 \mathrm{mg})$, and ion-exchanged water $(5.5 \mathrm{~mL})$ was stirred at $30^{\circ} \mathrm{C}$ for $30 \mathrm{~min}$. The amount of evolved $\mathrm{H}_{2}$ in the gas phase was measured by using gas chromatography (SHIMADZU GC-14B).

\section{Results and Discussions}

The crystallinity of aCuTi was investigated by XRD measurements. As shown in Fig. 2(a), the aCuTi exhibited a broad peak (halo peak) in the $35^{\circ}<2 \theta<45^{\circ}$ region but no sharp peak due to crystalline alloy was observed. This result indicates that the prepared aCuTi alloy has an amorphous structure. Figure 2(b), 2(c) exhibited the XRD pattern of Ti and $\mathrm{Cu}$. The peak of aCuTi is located between the two sharp XRD peaks assigned to $\mathrm{Cu}$ and Ti reflections. Samples of aCuTi were heated at $100-600^{\circ} \mathrm{C}$ under vacuum. Figure 3(a)-(g) show XRD patterns of $\operatorname{CuTi}(T)$, in which the increase of peak (halo) intensity upon increasing the heating temperature up to $300^{\circ} \mathrm{C}$ is observed. This confirms

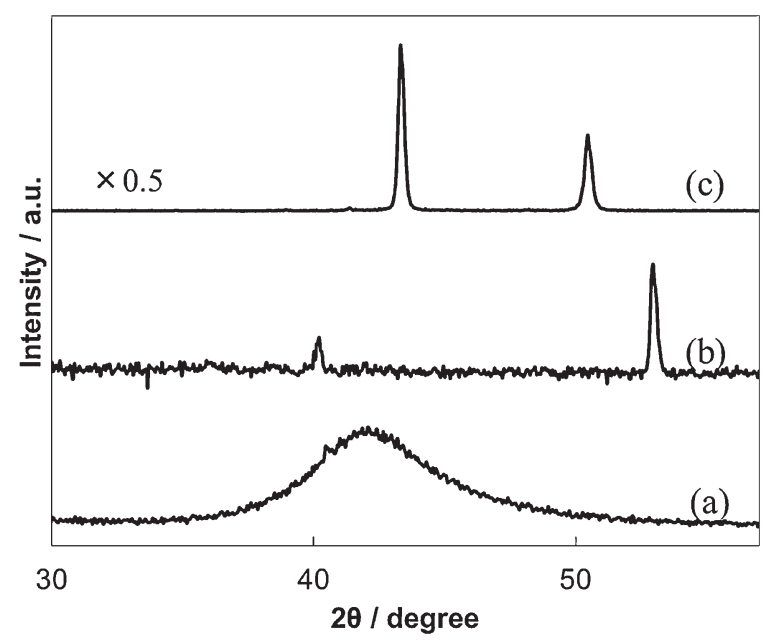

Fig. 2 XRD pattern of (a) aCuTi, (b) Ti sponge, and (c) Cu plate.

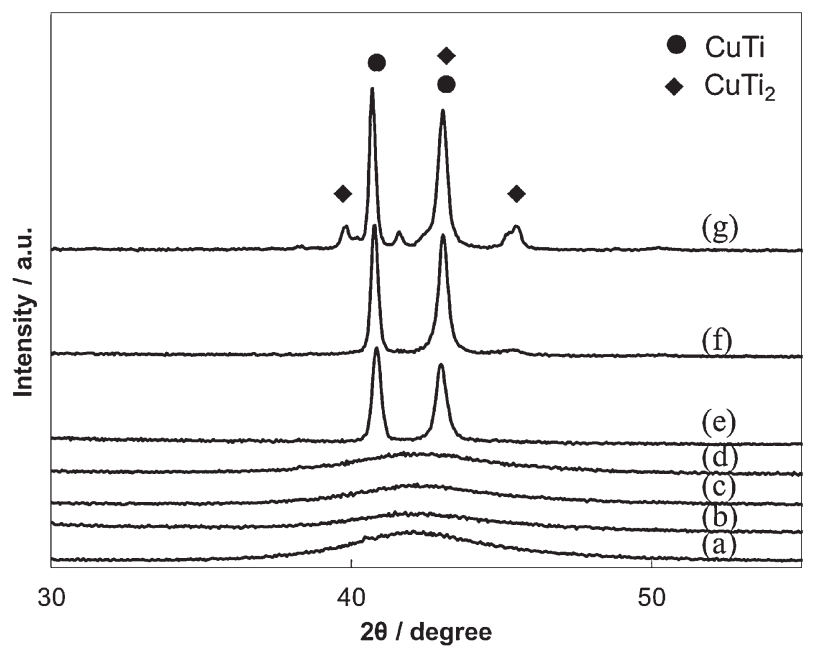

Fig. $3 \mathrm{XRD}$ pattern of $\mathrm{Cu}-\mathrm{Ti}$ alloys heated at various temperatures ((a) aCuTi, (b) CuTi(100), (c) CuTi(200), (d) CuTi(300), (e) CuTi(400), (f) $\mathrm{CuTi}(500)$, and (g) CuTi(600)).

Table 1 Surface area and atomic ratio of CuTi alloys treated with HF solution.

\begin{tabular}{lccccc}
\hline Catalysts & $\begin{array}{c}\text { Pre-treatment } \\
\text { temperature }\end{array}$ & $\begin{array}{c}\text { Concentration } \\
\text { of } \mathrm{HF} \\
\text { solution } \\
/{ }^{\circ} \mathrm{C}\end{array}$ & $\begin{array}{c}\text { Surface } \\
\text { area }\end{array}$ & $\begin{array}{c}\text { Surface atomic } \\
\text { ratio } \\
/ \%\end{array}$ \\
\hline $\mathrm{aCuTi}$ & None & None & 0.1 & 45 & 55 \\
$\mathrm{~s}-\mathrm{aCu}$ & None & 1 & 3.7 & 98 & 2 \\
$\mathrm{~s}-\mathrm{Cu}(300)$ & 300 & 1 & 7.9 & 98 & 2 \\
$\mathrm{~s}-\mathrm{Cu}(400)$ & 400 & 1 & 11.1 & 96 & 4 \\
$\mathrm{~s}-\mathrm{Cu}(600)$ & 600 & 1 & 9.1 & 92 & 8 \\
\hline
\end{tabular}

that these alloys have mainly amorphous phases. After heating at $400^{\circ} \mathrm{C}$, sharp peaks are observed in the same region, and they were assigned to the $\mathrm{CuTi}$ and $\mathrm{CuTi}_{2}$ crystalline phases, indicating that these alloys are composed mainly as crystalline phase.

The surface area and atomic ratio of aCuTi and skeletal $\mathrm{Cu}$ were evaluated by krypton physisorption and EDX analysis, respectively (Table 1). Surface area of aCuTi was 

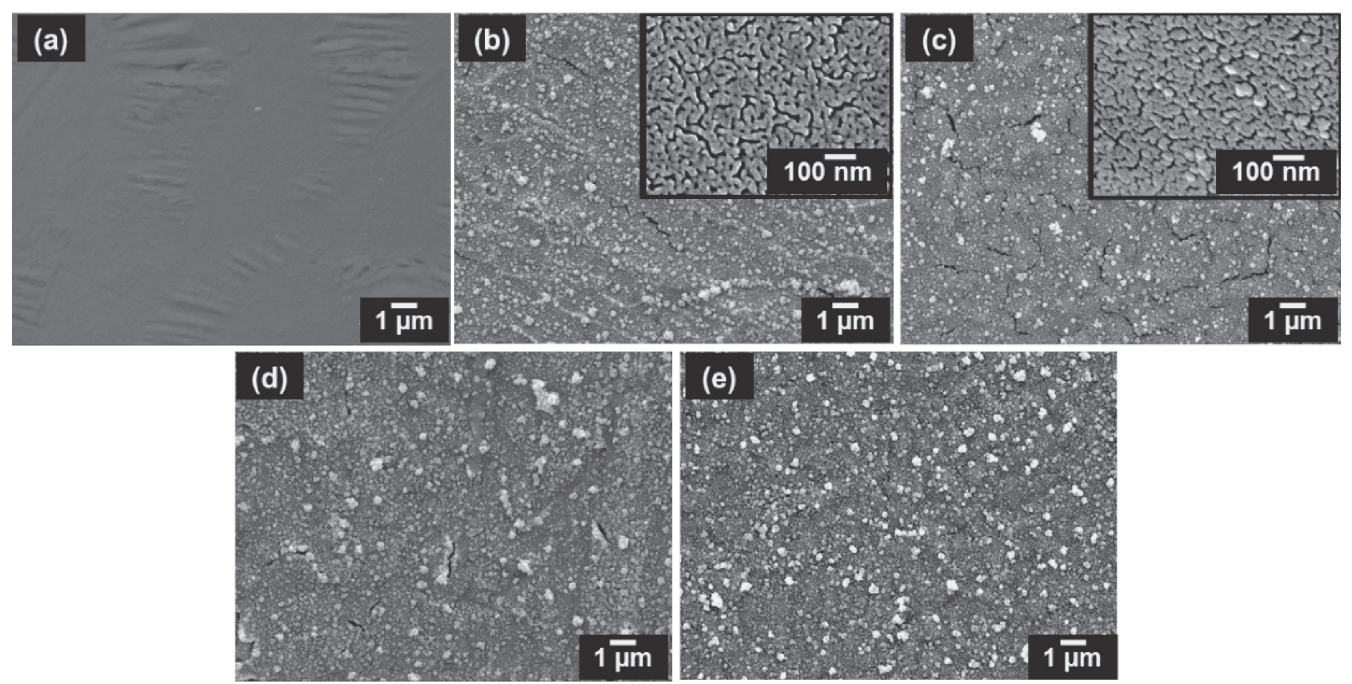

Fig. 4 FE-SEM images of samples; (a) aCuTi, (b) s-aCu, (c) s-Cu(300), (d) s-Cu(400), and (e) s-Cu(600).

ca. $0.1 \mathrm{~m}^{2} \cdot \mathrm{g}^{-1}$. After HF treatment, the surface area of $\mathrm{s}-\mathrm{aCu}$ drastically increased to $3.7 \mathrm{~m}^{2} \cdot \mathrm{g}^{-1}$. The surface area of skeletal $\mathrm{Cu}$ increased with increasing heating temperature up to $400^{\circ} \mathrm{C}$. The surface area of s-Cu(600) was slightly lower than $\mathrm{s}-\mathrm{Cu}(400)$. The heat treatment at the near crystallization temperature (ca. $397^{\circ} \mathrm{C}$ ) leads to high surface area. The composition of aCuTi was determined to be $\mathrm{Cu}(45$ atom\%) and $\mathrm{Ti}(55$ atom\%) by EDX analysis. After HF treatment of $\mathrm{aCuTi}$, the atomic ratio showed a significant decrease in the surface Ti concentration $(\mathrm{Cu}: \mathrm{Ti}=98: 2)$. Figure 3 showed the surface morphology of samples measured by Fieldemission scanning electron microscopy (FE-SEM). Smooth surface without any pores is observed on the surface of aCuTi as shown in Fig. 4(a). Figure 4(b)-(e) showed spongy surface, accompanied by a drastic decrease of Ti moieties. There are no significant differences in the sample's surface morphology in FE-SEM images, despite the fact that the surface area differ substantially between samples. The difference of surface area was deduced from the shape of skeletal $\mathrm{Cu}$ after $\mathrm{HF}$ treatment to $\mathrm{Cu}-\mathrm{Ti}$ alloy. $\mathrm{s}-\mathrm{aCu}$ and $\mathrm{s}-\mathrm{Cu}(300)$ which prepared from alloy in the amorphous states maintained the shape of ribbon. Whereas, the shape of $\mathrm{s}-\mathrm{Cu}(400)$ and $\mathrm{s}-\mathrm{Cu}(600)$ which prepared from alloy in the crystalline states broke into pieces. This is attributed to the difference of the crystallinity among the samples. Ti moieties in amorphous alloys were extracted uniformly from the surface, whereas $\mathrm{Ti}$ moieties in crystalline alloys were extracted significantly from the grain boundary. CuTi(400) might have polycrystalline grain and quite small size of grain, which shows the highest surface area. The surface area of $\mathrm{s}-\mathrm{Cu}(300)\left(7.9 \mathrm{~m}^{2} \cdot \mathrm{g}^{-1}\right)$ was larger than that of s$\mathrm{aCu}\left(3.7 \mathrm{~m}^{2} \cdot \mathrm{g}^{-1}\right)$, despite the fact that there were no visible differences in macroscopic structures and compositions between $\mathrm{s}-\mathrm{aCu}$ and $\mathrm{s}-\mathrm{Cu}(300)$. The increase of surface area might be resulted from the difference of atomic arrangement. Amorphous alloy has a thermodynamic non-equilibrium state. The heat treatment at appropriate temperature leads to an atomic migration and a short-range structural rearrangement in the amorphous alloy, which might be effective for the reduction of structural disorder and the increase of the surface

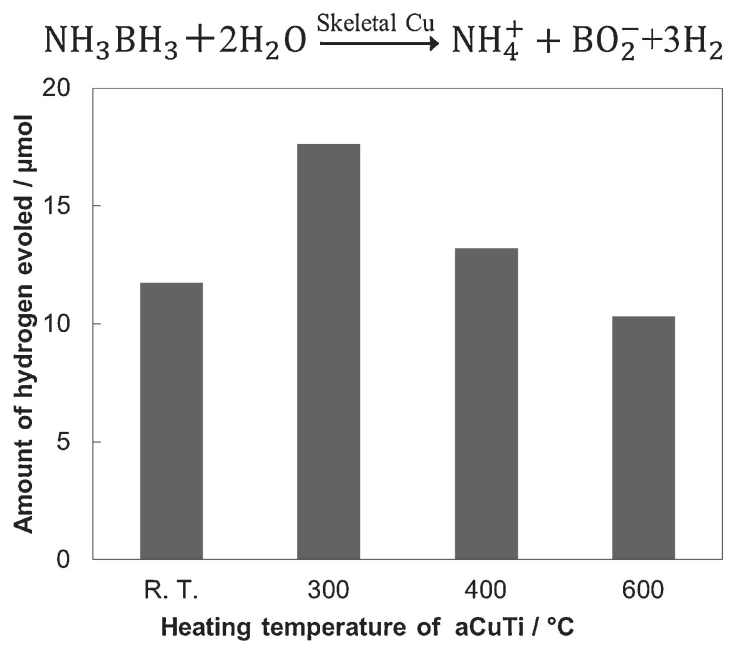

Fig. 5 Amount of evolved hydrogen on skeletal $\mathrm{Cu}$ catalysts prepared from $\mathrm{Cu}$-Ti amorphous alloy heated at various temperatures.

area. These results clearly show that skeletal $\mathrm{Cu}$ with high surface area was formed by selective extraction of Ti moieties from the aCuTi alloys by HF treatment.

The catalytic performances of samples were investigated in the hydrogen generation from ammonia borane. aCuTi was totally-inactive in this reaction. The amount of evolved hydrogen over s-Cu(300) was larger than that of the other samples, as shown in Fig. 5. The s-Cu(400) exhibited a lower catalytic activity than $\mathrm{s}-\mathrm{Cu}(300)$ despite the highest surface area of $\mathrm{s}-\mathrm{Cu}(400)$. The catalytic activities per surface area were shown in Fig. 6 to investigate the effect of the atomic arrangement of $\mathrm{Cu}-\mathrm{Ti}$ amorphous alloy on the catalytic activity of skeletal $\mathrm{Cu}$. The $\mathrm{s}-\mathrm{aCu}$ showed the highest catalytic activity per surface area. The catalytic activity per surface area decreased with increasing heating temperatures to aCuTi. For further consideration, the crystallinity of s-aCu and $\mathrm{s}-\mathrm{Cu}(600)$ were measured by XRD. As shown in Fig. 7, three peaks are observed, and they were assigned to the $\mathrm{Cu}$ phase and $\mathrm{Cu}_{2} \mathrm{O}$ phase which caused by the exposure to air of samples before XRD measurement. The comparison with the 


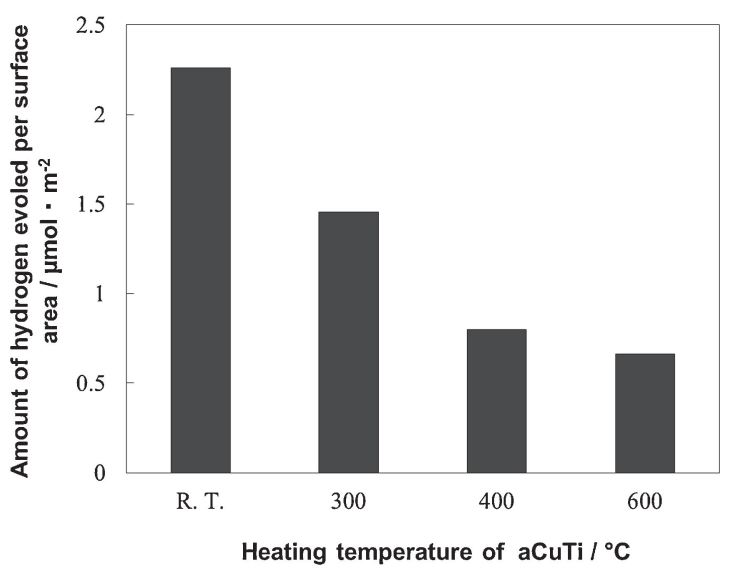

Fig. 6 Amount of evolved hydrogen per surface area on skeletal $\mathrm{Cu}$ catalysts prepared from $\mathrm{Cu}-\mathrm{Ti}$ amorphous alloy heated at various temperatures.

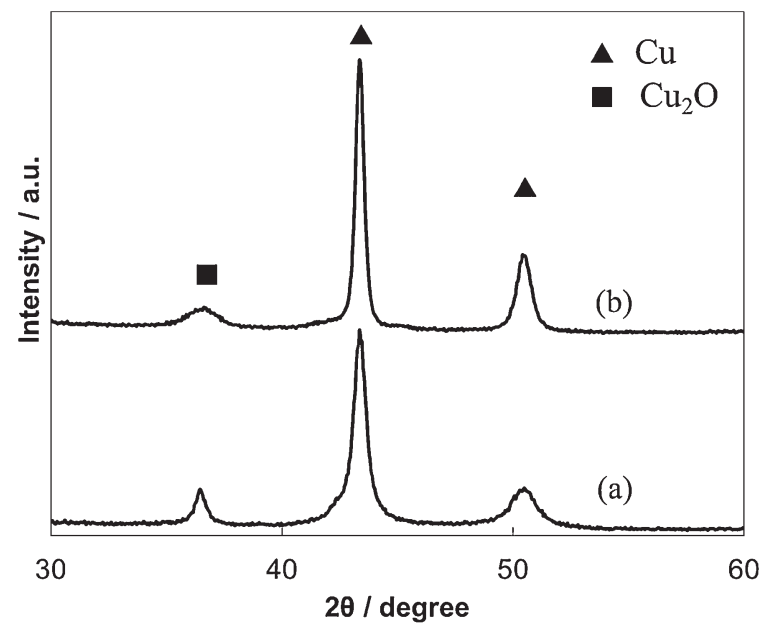

Fig. 7 XRD pattern of skeletal $\mathrm{Cu}((\mathrm{a}) \mathrm{s}-\mathrm{aCu}$ and (b) $\mathrm{s}-\mathrm{Cu}(600)$ ).

half width of the $\mathrm{Cu}$ peaks between $\mathrm{s}-\mathrm{aCu}$ and $\mathrm{s}-\mathrm{Cu}(600)$ revealed that $\mathrm{s}-\mathrm{aCu}$ had a low crystallinity. It is expected that $\mathrm{Ti}$ moieties of $\mathrm{Cu}$-Ti crystalline alloy were extracted more easily and faster than that of $\mathrm{Cu}-\mathrm{Ti}$ amorphous alloy due to the ordered atomic arrangement caused by the thermal treatment. The rapid extraction of Ti might facilitate the atomic rearrangements of $\mathrm{Cu}$, which leads to the high crystallinity of $\mathrm{s}-\mathrm{Cu}(600)$. From these results, it was assumed that low-coordination $\mathrm{Cu}$ atoms were present at a high concentration in the surface of $\mathrm{s}-\mathrm{aCu}$, which might be the cause of the high catalytic activity per surface area. To provide a comparison, the catalytic activity of $\mathrm{Cu}$ catalyst supported on $\mathrm{SiO}_{2}\left(\mathrm{Cu} / \mathrm{SiO}_{2}\right)$ was also evaluate; however, the $\mathrm{Cu} / \mathrm{SiO}_{2}$ showed a quite higher activity than that of the skeletal $\mathrm{Cu}$ prepared from $\mathrm{Cu}-\mathrm{Ti}$ amorphous alloy. This is due to the low surface area derived from ribbon-shaped structure of the $\mathrm{Cu}-\mathrm{Ti}$ amorphous alloy, while the powdery $\mathrm{Cu} / \mathrm{SiO}_{2}$ has a large surface area $\left(S_{\mathrm{BET}}=252 \mathrm{~m}^{2} \cdot \mathrm{g}^{-1}\right)$ and nano-sized $\mathrm{Cu}$ metal particles. It is not rational to compare these two catalysts under the same reaction conditions. A further comparative study using appropriate reference catalysts such as Raney $\mathrm{Cu}$ and powder $\mathrm{Cu}$ is now under investigation and would be reported elsewhere.

\section{Conclusion}

Skeletal $\mathrm{Cu}$ catalysts prepared from $\mathrm{Cu}-\mathrm{Ti}$ alloys were active in the hydrogen generation reaction from ammonia borane. The catalytic activity per surface area depends on the atomic arrangement of precursor which were preferable in the amorphous state. The surface area of skeletal $\mathrm{Cu}$ prepared from $\mathrm{Cu}-\mathrm{Ti}$ alloy heated at near crystallization temperature (ca. $397^{\circ} \mathrm{C}$ ) was quite high because of the existence many fine crystal grains and remarkable extraction along with the grain boundary. The heat treatment at $300^{\circ} \mathrm{C}$ which is moderate temperature somewhat lower than crystallization temperature maintained the amorphous structure and a superior the surface area of skeletal $\mathrm{Cu}$, which led to the highest catalytic activity.

\section{Acknowledgments}

This study was supported by a Grant-in-Aid for Scientific Research (KAKENHI, No. 262209110) from the Ministry of Education, Culture, Sports, Science and Technology (MEXT), Japan. One of the authors, Ai Nozaki, is supported by JSPS Research Fellowships for Young Scientists.

\section{REFERENCES}

1) G. S. Samuelsen, V. L. Garik and G. B. L. Smith: J. Am. Chem. Soc. 72 (1950) 3872-3874.

2) J. Erlebacher, M. J. Aziz, A. Karma, N. Dimitrov and K. Sieradzki: Nature 410 (2001) 450-453.

3) V. Zielasek, B. Jürgens, C. Schulz, J. Biener, M. M. Biener, A. V. Hamza and M. Bäumer: Angew. Chem. Int. Ed. 45 (2006) 8241-8244.

4) G. S. Samuelsen, V. L. Garik and G. B. L. Smith: J. Am. Chem. Soc. 72 (1950) 3872-3874.

5) C. Xu, J. Su, X. Xu, P. Liu, H. Zhao, F. Tian and Y. Ding: J. Am. Chem. Soc. 12 (2007) 42-43.

6) T. Fujita, P. Guan, K. McKenna, X. Lang, A. Hirata, L. Zhang, T. Tokunaga, S. Arai, Y. Yamamoto, N. Tanaka, Y. Ishikawa, N. Asao, Y. Yamamoto, J. Erlebacher and M. Chen: Nature Mater. 11 (2012) 775780 .

7) C. Xu, Q. Hao and H. Duan: J. Mater. Chem. A 2 (2014) 8875-8880.

8) M. Yan, T. Jin, Q. Chen, H. E. Ho, T. Fujita, L.-Y. Chen, M. Bao, M.-W. Chen, N. Asao and Y. Yamamoto: Org. Lett. 15 (2013) 14841487.

9) M. Yan, T. Jin, Y. Ishikawa, T. Minato, T. Fujita, L.-Y. Chen, M. Bao, N. Asao, M.-W. Chen and Y. Yamamoto: J. Am. Chem. Soc. 134 (2012) 17536-17542.

10) M. M. Biener, J. Biener, A. Wichmann, A. Wittstock, T. F. Baumann, M. Bäumer and A. V. Hamza: Nano Lett. 11 (2011) 3085-3090.

11) A. Nozaki, T. Kamegawa, T. Ohmichi and H. Yamashita: ChemPhysChem 14 (2013) 2534-2538.

12) A. Nozaki, T. Kamegawa, T. Ohmichi and H. Yamashita: Bull. Chem. Soc. Jpn. 86 (2013) 1002-1004.

13) W. Klement, R. H. Willens and P. Duwez: Nature 187 (1960) 869-870.

14) C. Suryanarayana: Prog. Mater. Sci. 46 (2001) 1-184.

15) J. van Wonterghem, S. Morup, C. J. W. Koch, S. W. Charles and S. Wells: Nature 322 (1986) 622-623.

16) C. A. Schuh, T. C. Hufnagel and U. Ramamurty: Acta Mater. 55 (2007) 4067-4109.

17) A. Inoue: Acta Mater. 48 (2000) 279-306.

18) T. Masumoto, H. Kimura and A. Inoue: Mater. Sci. Eng. 23 (1976) $141-144$.

19) K. S. Suslick, S.-B. Choe, A. A. Cichowlas and M. W. Grinstaff: Nature 353 (1991) 414-416.

20) V. Kesavan, P. S. Sivanand, S. Chandrasekaran, Y. Koltypin and A. Gedanken: Angew. Chem. Int. Ed. 38 (1999) 3521-3523.

21) X. B. Zhang, J. M. Yan, S. Han, H. Shioyama and Q. Xu: J. Am. Chem. 
Soc. 131 (2009) 2778-2779.

22) A. Yokoyama, H. Komiyama, H. Inoue, T. Matsumoto and H. M. Kimura: J. Catal. 68 (1981) 355-361.

23) H. Li, F. Dong, M. Xiong, H. Li, P. Li and X. Zhou: Adv. Synth. Catal. 353 (2011) 2131-2136.

24) W. E. Brower, Jr., M. S. Matyjaszczyk, T. L. Pettit and G. V. Smith: Nature 301 (1983) 497-499.

25) A. Baiker, M. Maciejewski, S. Tagliaferri and P. Hug: J. Catal. 151 (1995) 407-419.

26) Á. Molnár, G. V. Smith and M. Bartók: J. Catal. 101 (1986) 540-544.

27) J. Fang, X. Chen, B. Liu, S. Yan, M. Qiao, H. Li, H. He and K. Fan:
J. Catal. 229 (2005) 97-104.

28) H. Li, J. Liu, S. H. Xie, M. H. Qiao, W. L. Dai and H. X. Li: J. Catal. 259 (2008) 104-110.

29) T. Kulik: J. Non-Cryst. Solids 287 (2001) 145-161.

30) J. M. Yan, X. B. Zhang, T. Akita, M. Haruta and Q. Xu: J. Am. Chem. Soc. 132 (2010) 5326-5327.

31) X. Gu, Z. H. Lu, H. L. Jiang, T. Akita and Q. Xu: J. Am. Chem. Soc. 133 (2011) 11822-11825.

32) J. M. Yan, X. B. Zhang, S. Han, H. Shioyama and Q. Xu: Angew. Chem. Int. Ed. 47 (2008) 2287-2289. 